\title{
TEMPERATURE STABLE, POST-PROCESS TUNABLE, HIGH Q HBARS AT 3 5 GHZ
}

\author{
Hongyu Yu, Hao Zhang, Wei Pang, and Eun Sok Kim \\ Department of Electrical Engineering \\ University of Southern California \\ Los Angeles, CA 90089-0271, U.S.A.
}

\begin{abstract}
This paper describes a temperature-compensated Highovertone Bulk Acoustic Resonator (HBAR) with a loaded quality factor (Q) of 801 and 545 at $3.427 \mathrm{GHz}$ and $4.597 \mathrm{GHz}$, respectively. The HBAR is composed of an $\mathrm{Al} / \mathrm{ZnO} / \mathrm{Al}$ resonator on a $\mathrm{SiO}_{2} / \mathrm{Si} / \mathrm{SiO}_{2}$ diaphragm where a thermally grown $\mathrm{SiO}_{2}$ with positive temperature-coefficient-of-frequency (TCF) compensates the negative TCF of the rest of the resonator layers. The HBAR's TCF reaches zero at a specific temperature, and is lower than $1 \mathrm{ppm} /{ }^{\circ} \mathrm{C}$ over a $30^{\circ} \mathrm{C}$ temperature span, where the TCF is about 100 times better than the value obtainable with an un-compensated $\mathrm{Al} / \mathrm{ZnO} / \mathrm{Al}$ Film Bulk Acoustic Resonator (FBAR). Also, the resonant frequency of the HBAR as well as its TCF is shown to be tunable by adding additional $\mathrm{SiN}$ and/or $\mathrm{SiO}_{2}$ layer after fabrication.
\end{abstract}

\section{INTRODUCTION}

There are three types of Bulk Acoustic Wave (BAW) resonators based on piezoelectric film: micromachined Film Bulk Acoustic Resonator (FBAR), Solidly Mounted Resonator (SMR) and High-overtone Bulk Acoustic Resonator (HBAR) [1 4]. Most BAW resonators are composed of metal/piezofilm/metal on top of a thin diaphragm or a thick substrate, and have shown a quality (Q) factor greater than hundreds (even tens of thousands in case of HBAR) at a resonant frequency of 0.5 to $10 \mathrm{GHz}$. The resonant frequency is predominantly determined by the thickness of the piezoelectric film. With their inherently high Q, BAW resonators are ideally suited for filters and oscillators at $\mathrm{GHz}$, since the $\mathrm{Q}$ determines the insertion loss and phase noise for filters and oscillators, respectively.

Since Agilent mass-produced FBAR-based duplexer filters for mobile phones in 2000, FBARs are widely used for RF frontend filters for mobile phones. Similar filters based on SMR recently have joined the mobile phone market. On the other hand, HBAR remains to be used only for niche oscillator applications, though its $Q$ can be made much higher than FBAR and SMR, mainly due to its multiple resonances and low electromechanical coupling coefficients.

Chip-Scale Atomic Clock (CSAC) enables miniature (and low power consuming) time reference for high security communication and jam-resistant global-positioning-system receiver. Since CSAC requires a very high Q resonator for its local oscillator, HBAR-based voltage controlled oscillators (VCO) is ideally suited for CSAC, where the oscillation frequency of particular interest is $3.4 \mathrm{GHz}$ or $4.6 \mathrm{GHz}$ for different system design topologies.

However, for HBAR-based VCO to be used for CSAC's local oscillator, the resonator must be very stable in temperature. For example, the resonant frequency shift of the resonator should not exceed $20 \mathrm{ppm}$ over 60 to $80^{\circ} \mathrm{C}$, which means the temperature coefficient of frequency (TCF) of the resonator should be less than
$1 \mathrm{ppm} /{ }^{\circ} \mathrm{C}$ (a conventional $\mathrm{Al} / \mathrm{ZnO} / \mathrm{Al}$ stand-alone resonator has a TCF of about $\left.-70 \mathrm{ppm} /{ }^{\circ} \mathrm{C}[5]\right)$.

To reduce HBAR's TCF, the following techniques have been explored and reported. A heater was embedded into an HBAR [6] to tune the resonant frequency to compensate the TCF. But this approach consumes large power and lacks repeatability. Another technique for HBAR is to use a capacitor (having a temperature coefficient in opposite sign to that of the HBAR's clamped capacitance) in series with the HBAR. The achievable TCF of an HBAR with this approach is limited by available capacitor.

The most promising technique for temperature compensation of a bulk acoustic resonator is to use a support layer (e.g., $\mathrm{SiO}_{2}$ or Elinvar) that has TCF opposite to that of the piezoelectric layer for FBAR $[7,8]$. No literature is found on temperature compensating HBAR with this method of incorporating a temperaturecompensating layer. This paper describes HBAR with temperature-compensating $\mathrm{SiO}_{2}$ layer, particularly their measured TCF's, timing stabilities and the post tuning ability.

\section{THEORY}

The resonant frequencies of a HBAR resonator is predominantly determined by acoustic-wave traveling time in the resonator, and are

$$
f_{r} \approx \frac{N}{2\left(d_{\text {piezo }} / V_{\text {piezo }}+d_{\text {elec }} / V_{\text {elec }}+d_{\text {substrate }} / V_{\text {substrate }}\right)^{-1}}
$$

where $d_{\text {piezo }}, d_{\text {elec }}, d_{\text {substrate }}$ are the thicknesses of the piezomaterial $(\mathrm{ZnO})$, electrodes $(\mathrm{Al})$, and diaphragm $\left(\mathrm{SiO}_{2}\right)$ (or substrate $\left.\left(\mathrm{SiO}_{2} / \mathrm{Si} / \mathrm{SiO}_{2}\right)\right)$, respectively, while $V_{\text {piezo }}, V_{\text {elec }}$ and $V_{\text {substrate }}$ are the acoustic velocities in the piezomaterial, electrodes, and diaphragm (or substrate), respectively. The dependence of the resonant frequency on temperature mainly comes from the acoustic velocity's dependence on temperature. The acoustic velocity is equal to $\sqrt{E / \rho}$ where $E$ and $\rho$ are Young's modulus and mass density, respectively. For most materials (such as $\mathrm{Al}, \mathrm{Si}$ and $\mathrm{ZnO}$ ) Young's modulus decreases as temperature increases, causing negative TCF for a BAW resonator.

However, due to the unique crystalline structure, the Young's modulus of $\mathrm{SiO}_{2}$ increases as temperature increases, resulting in a positive TCF. Thus, $\mathrm{SiO}_{2}$ layer can be used for compensating a negative $\mathrm{TCF}$ of $\mathrm{Al} / \mathrm{ZnO} / \mathrm{Al} / \mathrm{Si} \mathrm{HBAR}$.

We build an $\mathrm{HBAR}$ with $\mathrm{Al} / \mathrm{ZnO} / \mathrm{Al}$ on $\mathrm{SiO}_{2} / \mathrm{Si} / \mathrm{SiO}_{2}$ substrate (which is actually a diaphragm). Most of the resonator's acoustic energy is stored in the relatively thick single crystalline $\mathrm{Si}$ layer where the acoustic loss is much less than $\mathrm{ZnO}$ or Al. Hence, the resonator's Q is mostly determined by the single crystalline $\mathrm{Si}$, and can be much higher than FBAR. The thermally grown $\mathrm{SiO}_{2}$ layers below and above the Si layer are to compensate the negative TCF's of $\mathrm{ZnO}, \mathrm{Al}$ and $\mathrm{Si}$. Due to the complicated structure and acoustic energy distribution in the HBAR, there has not been an effective model to accurately predict the TCF of the HBAR, and 
we have fabricated HBARs with various multilayer thickness ratios to obtain optimum TCF experimentally.

\section{FABRICATION AND TESTING}

The temperature compensated HBARs are fabricated on a Silicon-on-Insulator (SOI) wafer with the fabrication steps shown in Fig. 1. After obtaining a silicon diaphragm (out of the silicon device layer of SOI) by TMAH, $\mathrm{XeF}_{2}$ and buffered HF etching (in that order) on an SOI wafer, we thermally grow wet $\mathrm{SiO}_{2}$ on the device silicon layer to form $\mathrm{SiO}_{2} / \mathrm{Si} / \mathrm{SiO}_{2}$ diaphragm. Then bottom $0.1 \mu \mathrm{m} \mathrm{Al}$ is evaporated on the $\mathrm{SiO}_{2}$ layer and patterned, followed by deposition of $0.68 \mu \mathrm{m}$ thick $\mathrm{ZnO}$ in a RF sputtering system with $10 \mathrm{mTorr}$ Argon and Oxygen gas mixture $(50 \% / 50 \%)$ at $300^{\circ} \mathrm{C}$ and $300 \mathrm{~W}$. After patterning the $\mathrm{ZnO}, 0.1 \mu \mathrm{m}$ thick top $\mathrm{Al}$ electrode is evaporated and patterned. The bottom $\mathrm{Al}, \mathrm{ZnO}$, and top $\mathrm{Al}$ on top of the diaphragm form the wave-generating layers of an HBAR.
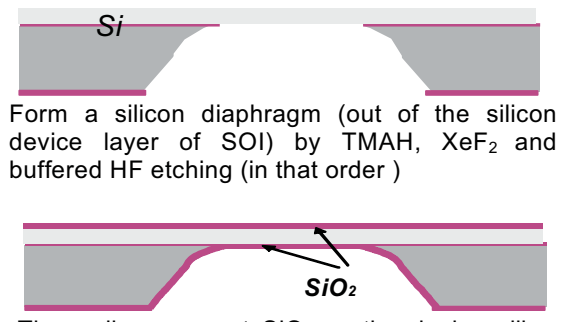

Thermally grow wet $\mathrm{SiO}_{2}$ on the device silicon layer to form $\mathrm{SiO}_{2} / \mathrm{Si} / \mathrm{SiO}_{2}$ diaphragm.

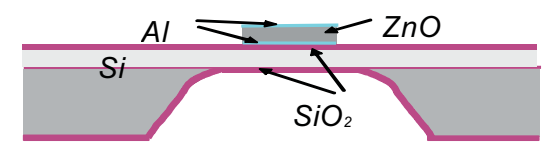

Deposit and pattern bottom $\mathrm{Al}, \mathrm{ZnO}$ and top $\mathrm{Al}$ on top of the diaphragm for the wave-generating layers of a HBAR

Figure 1 Brief fabrication process for the temperature compensated HBAR

The fabricated resonators are characterized with HP8753D network analyzer with Cascade microwave micropositioner and probes (for impedance measurement) and Instec's hot/cold chuck (for temperature variation). We have developed a Labview program to acquire data from the network analyzer and analyze it by curve fitting to monitor HBAR's resonant frequencies. The noise floor of this method is around $0.5 \mathrm{ppm}$, which is good enough for measuring the dependence of the HBAR's resonant frequency on temperature.

\section{RESULTS AND DISCUSSION}

HBARs with various top-view shapes and sizes (Fig. 2) along with various thickness ratios have been fabricated and tested. The testing results show little difference among different top-view shapes, but the top-view dimension of the HBAR affects the Q much. The HBAR with $100 \mu \mathrm{m}$ long sides is measured to have the highest $\mathrm{Q}$ at 3 to $5 \mathrm{GHz}$.
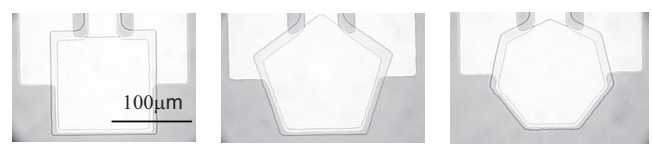

Figure 2 Top-view photos of the fabricated HBARs on $\mathrm{SiO}_{2} / \mathrm{Silicon} / \mathrm{SiO}_{2}$
The TCF of the HBAR is directly related to the thickness ratios among various structure layers. Figure 3 shows the measured TCF's at about $80^{\circ} \mathrm{C}$ for different thickness ratios for the $\mathrm{SiO}_{2} / \mathrm{Si} / \mathrm{SiO}_{2}$ multi-layers for the HBAR with $\mathrm{Al} / \mathrm{ZnO} / \mathrm{Al}$ having thicknesses of $0.1 \mu \mathrm{m} / 0.68 \mu \mathrm{m} / 0.1 \mu \mathrm{m}$ (for $3.4 \mathrm{GHz}$ ) and $0.1 \mu \mathrm{m} / 0.48 \mu \mathrm{m} / 0.1 \mu \mathrm{m}$ (for $4.6 \mathrm{GHz}$ ), respectively. The measured TCFs depend linearly on the thickness ratio between the positive TCF layer $\left(\mathrm{SiO}_{2}\right)$ and the effective negative TCF layer (obtained by converting the $\mathrm{Al}, \mathrm{ZnO}$ and $\mathrm{Si}$ layers to an equivalent $\mathrm{Si}$ layer). The ratios of 0.28 and 0.35 produce zero TCF's for the 4.6 and 3.4GHz HBARs, respectively.
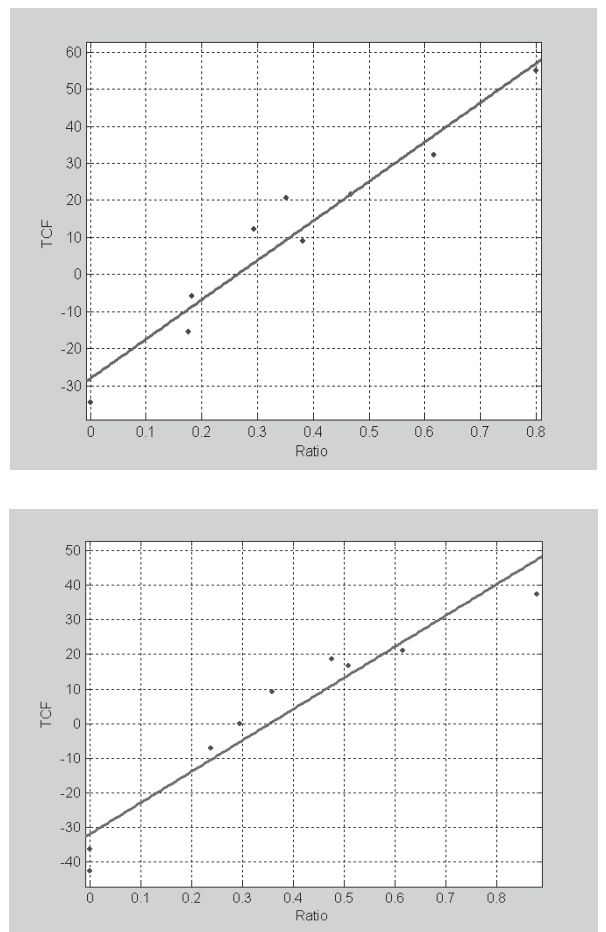

Figure 3 Measured TCF $\left(\mathrm{ppm} /{ }^{\circ} \mathrm{C}\right.$ ) at $4.6 \mathrm{GHz}($ top) and $3.4 \mathrm{GHz}$ (bottom) vs. the ratio of the +TCF layer thickness to the $-\mathrm{TCF}$ layer thickness.

The zero TCF HBAR with $\mathrm{Al} / \mathrm{ZnO} / \mathrm{Al} / \mathrm{SiO}_{2} / \mathrm{Si} / \mathrm{SiO}_{2}$ $(0.1 \mu \mathrm{m} / 0.68 \mu \mathrm{m} / 0.1 \mu \mathrm{m} / 1.7 \mu \mathrm{m} / 9.9 \mu \mathrm{m} / 1.7 \mu \mathrm{m})$ is measured to have eight resonant frequencies between 3 and $5 \mathrm{GHz}$ (Fig.2). The HBAR has different TCF's at these frequencies, which are shown in the Table 2. The reason for the different TCF's is the different acoustic energy distribution along the HBAR thickness. The more acoustic standing wave energy in the positive TCF layer $\left(\mathrm{SiO}_{2}\right)$, the more positive of the whole HBAR's TCF.

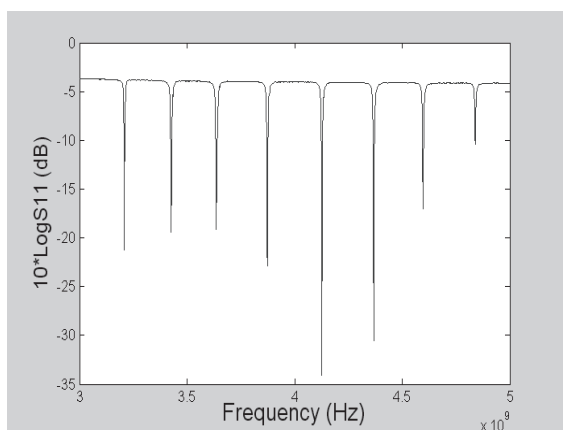

Figure 4 Measured $S_{11}$ vs. frequency of the HBAR. 
Table 1 TCFs at five different resonant frequencies of the HBAR on $\mathrm{SiO}_{2} / \mathrm{SI} / \mathrm{SiO}_{2}$

\begin{tabular}{|c|c|c|c|c|c|c|c|}
\hline $\begin{array}{c}\text { Resonant } \\
\text { Frequency } \\
(\mathrm{GHz})\end{array}$ & 3.208 & 3.427 & 3.636 & 3.873 & 4.124 & 4.366 & 4.597 \\
\hline $\begin{array}{c}\mathrm{TCF}\left(\mathrm{ppm} /{ }^{\circ} \mathrm{C}\right) \\
\text { at } 72.5^{\circ} \mathrm{C}\end{array}$ & -1.87 & 0 & -3.95 & -10.1 & -10.7 & -6.5 & -1.84 \\
\hline
\end{tabular}

The HBAR is measured to have impedance variation from 3.416 to $3.428 \mathrm{GHz}$ as shown in Fig. 5. The highest loaded Q's at the parallel resonant frequency $(3.4271 \mathrm{GHz})$ and series resonant frequency $(3.4215 \mathrm{GHz})$ are measured to be 801 and 660 , respectively. The electromechanical coupling coefficient $\left(\mathrm{K}_{\mathrm{t}}^{2}\right)$ is $0.41 \%$. If the series resistance is de-embedded [9], the unloaded Q's are 821 and 1045 at the parallel and series resonant frequencies, respectively.

At the parallel and series resonant frequencies near 3.4 $\mathrm{GHz}$, the HBAR is measured to have a TCF of 1.0 to $-0.8 \mathrm{ppm} /{ }^{\circ} \mathrm{C}$ between 60 and $90^{\circ} \mathrm{C}$, where the zero TCF point is at $72.5^{\circ} \mathrm{C}$. The parallel resonant frequency vs. temperature (from room temperature to $125^{\circ} \mathrm{C}$ ) is shown in Fig. 6. The total parallel resonant frequency change between 53 and $90^{\circ} \mathrm{C}$ (over $37^{\circ} \mathrm{C}$ range) is $36.6 \mathrm{kHz}$, mere $10.7 \mathrm{ppm}$. And from room temperature $\left(27^{\circ} \mathrm{C}\right)$ to $120{ }^{\circ} \mathrm{C}$, the total resonant frequency change is $312 \mathrm{kHz}$, which is $91 \mathrm{ppm}$.

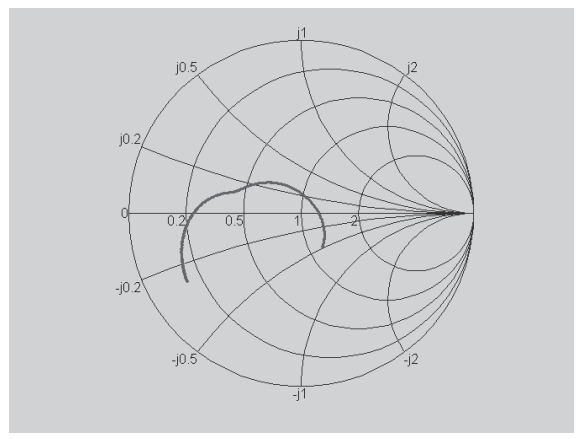

Figure 5 Measured Smith-chart impedance from 3.416 to $3.428 \mathrm{GHz}$.

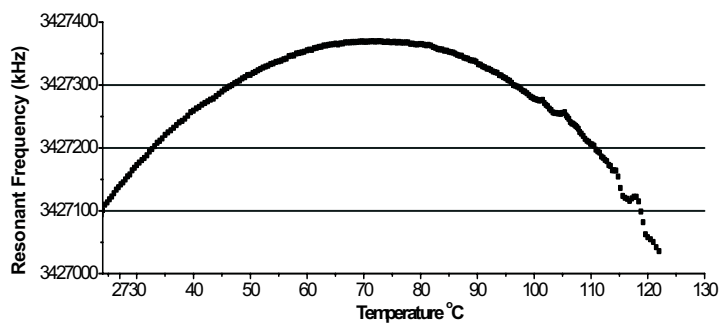

Figure 6 Measured resonant frequency vs. temperature for the HBAR at $3.427 \mathrm{GHz}$.

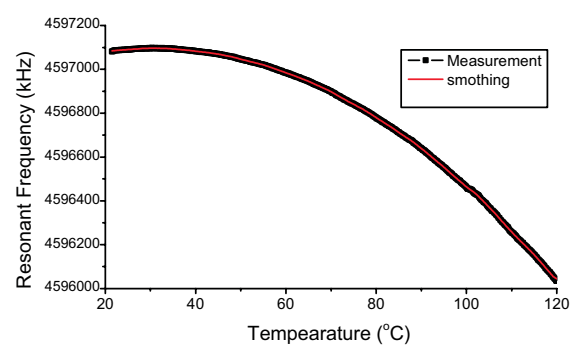

Figure 7 Measured resonant frequency vs. temperature for the HBAR at $4.597 \mathrm{GHz}$
The same HBAR yields a zero TCF at $32.8^{\circ} \mathrm{C}$ (Fig. 7) with a loaded parallel Q of 545 for a parallel resonant frequency of 4.597 GHz. The HBAR's parallel resonant frequency varies a total of $228 \mathrm{ppm}$ at $4.597 \mathrm{GHz}$ over a wide temperature span of 24 to $125^{\circ} \mathrm{C}$. Note that the resonant frequency of a typical siliconsupported $\mathrm{ZnO} H B A R$ varies about 3,700ppm over $24-125^{\circ} \mathrm{C}$.

The TCFs at the parallel and series resonant frequencies of the HBAR are measured to vary with temperature as shown in Fig 8. The measurement shows that the TCF changes linearly from $4 \mathrm{ppm} /{ }^{\circ} \mathrm{C}$ at $23^{\circ} \mathrm{C}$ to around $-4 \mathrm{ppm} /{ }^{\circ} \mathrm{C}$ at $122^{\circ} \mathrm{C}$, with a slope of $0.079 \mathrm{ppm} /{ }^{\circ} \mathrm{C} /{ }^{\circ} \mathrm{C}$. With this linear variation of the $\mathrm{TCF}$, we cannot obtain a very low TCF from $-50^{\circ} \mathrm{C}$ to $120^{\circ} \mathrm{C}$. Thus, in an effort to obtain an "S-shape" in the resonant frequency vs. temperature curve, we have applied a DC voltage to piezoelectrically stiffen the HBAR to see if the voltage can affect the TCF vs. temperature curve. As can be seen in Fig. 9, the DC voltage is measured to change the resonant frequency of the HBAR. However, we have observed no change in the TCF curve by an applied DC voltage.

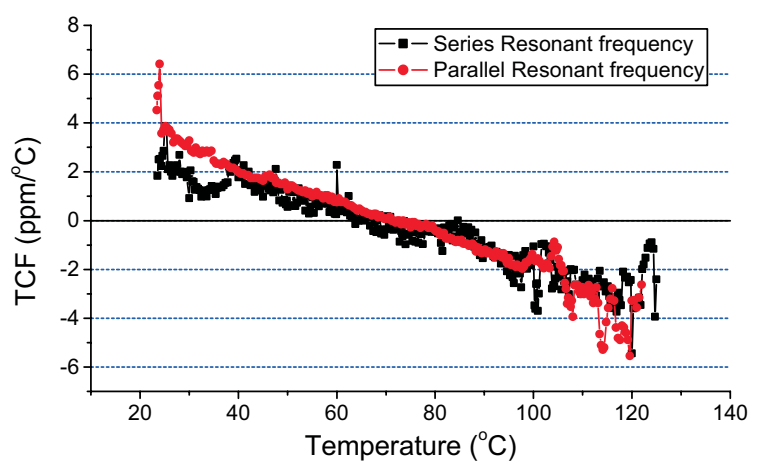

Figure 8 Measured TCF at parallel resonant frequency (gray) and series resonant frequency (black) vs. temperature of the HBAR.

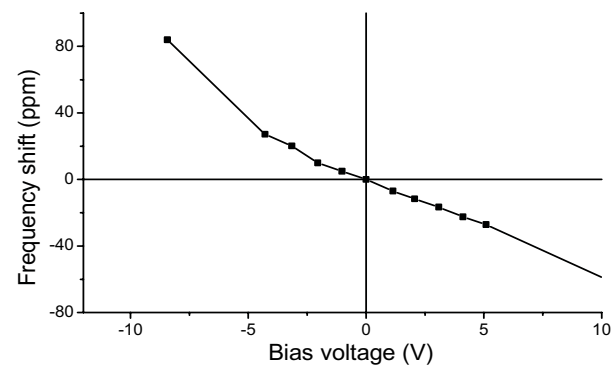

Figure 9 Measured HBAR's resonant frequency vs. applied DC voltage.

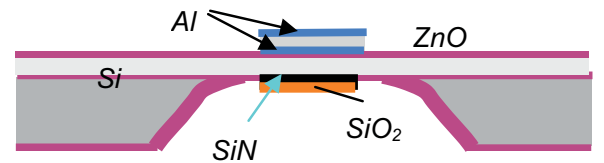

Figure 10 Post-process tuning by additional layers of PECVD SiN and $\mathrm{SiO}_{2}$ on the backside of HBAR

Due to the sensitivity of HBAR's resonant frequency and TCF to the structure's multilayer thicknesses, the fabrication process needs to be controlled critically to meet the frequency and TCF demand for the devices. Thus, we have developed a postprocess, frequency and TCF tuning method by depositing PECVD $\mathrm{SiN}$ and $\mathrm{SiO}_{2}$ layers on the backside of the HBAR (Fig. 10). The measured data show that the additional layers change the HBAR's resonant frequency and TCF at a different rate. Thus, any desired resonant frequency and TCF can be obtained by combining different thicknesses of the $\mathrm{SiN}$ and $\mathrm{SiO}_{2}$. For example, an 
additional $0.6 \mu \mathrm{m}$ thick $\mathrm{SiN}$ and $0.4 \mu \mathrm{m}$ thick $\mathrm{SiO}_{2}$ on $\mathrm{Al} / \mathrm{ZnO} / \mathrm{Al} / \mathrm{SiO}_{2} / \mathrm{Si} / \mathrm{SiO}_{2}(0.1 \mu \mathrm{m} / 0.68 \mu \mathrm{m} / 0.1 \mu \mathrm{m} / 1.7 \mu \mathrm{m} / 3.9 \mu \mathrm{m} / 1.7 \mu$ $\mathrm{m}) \mathrm{HBAR}$ makes the HBAR have a $3.427 \mathrm{GHz}$ resonant frequency and zero TCF at $75^{\circ} \mathrm{C}$ with a same high Q (a fine tuning from a resonant frequency of $3.601 \mathrm{GHz}$ and TCF of $13.9 \mathrm{ppm} /{ }^{\circ} \mathrm{C}$ ).

For CSAC, an HBAR-based voltage controlled oscillator (VCO) can be used for keeping a short-term stability of the clock, while the atomic emission unit keeps the long-term stability. Nevertheless, the long-term (as well as short-term) stability is still very important for HBARs. For testing the short-term stability, we keep the temperature compensated $\mathrm{HBAR}$ at $72.5^{\circ} \mathrm{C}$, where the TCF of HBAR is 0 , to minimize the effect from the temperature fluctuation. Figure 11 shows that the parallel frequency fluctuation is measured to be about $3.3 \mathrm{ppm}$ and $6.7 \mathrm{ppm}$ within 90 minutes and 8 hours, respectively.

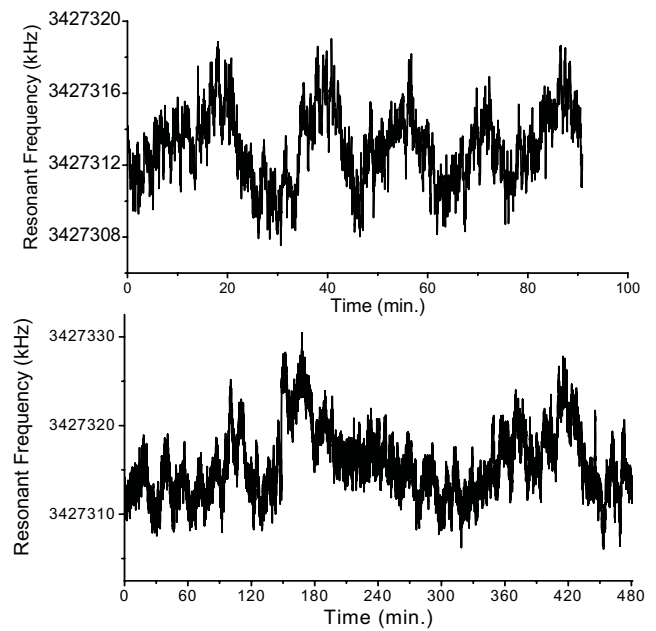

Figure 11 Measured short-term stability of the temperature compensated HBAR.

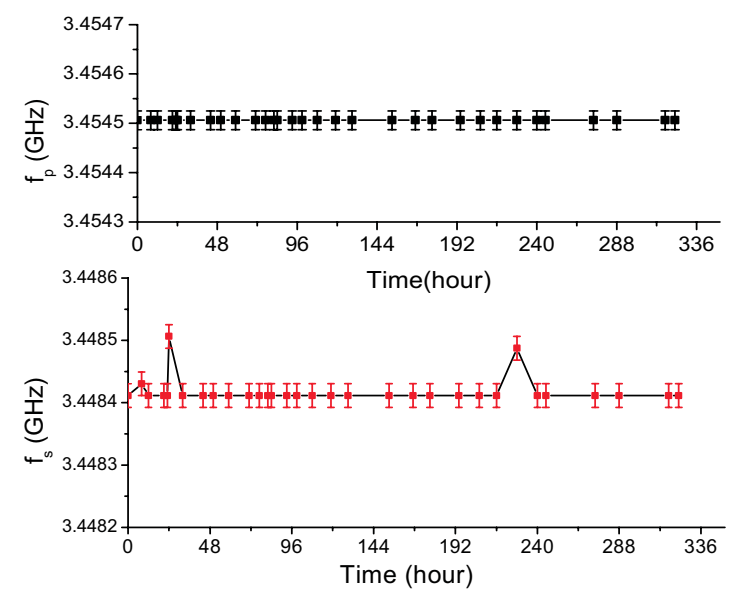

Figure 12 Measured long-term stability of the temperature compensated HBAR.

To test the long-term stability we place the HBAR on a printed circuit board (PCB), and connect it to the network analyzer through an SMA connector. The network analyzer applies a constant power of $-3.8 \mathrm{dBm}$ to the HBAR to obtain the $\mathrm{S}_{11}$. Though the HBARs used for the short-term and long-term stability tests are from the same wafer and have similar TCF parameters, their resonant frequencies are different. Figure 12 shows that the parallel resonant frequency remains constant (within the measurement error of $11 \mathrm{ppm}$ ) over 330 hours, but the series resonant frequency varies about $33 \mathrm{ppm}$ over the same period of time. The reason for the fluctuation of the series resonant frequency is that there is a spurious resonance very near the series resonant frequency, which may have much higher TCF than the series resonant frequency.

\section{CONCLUSION}

In this paper we describe the experimental verification that using $\mathrm{SiO}_{2}$ layer to compensate the HBAR's TCF is effective. A single HBAR supported on a $\mathrm{SiO}_{2} / \mathrm{Si} / \mathrm{SiO}_{2}$ substrate/diaphragm (made on an SOI wafer) possesses a very low TCF and a high Q of about 800 and 545 at $3.4 \mathrm{GHz}$ and $4.6 \mathrm{GHz}$, respectively. Also the post-process tuning method is shown to be effective in meeting the frequency and TCF specifications without having to optimize the complicated thickness ratios for mass production. Therefore, using $\mathrm{SiO}_{2}$ to compensate the HBAR's TCF is a very promising method to obtain a low TCF and high $\mathrm{Q}$ resonator at 3 - $5 \mathrm{GHz}$. Thus temperature-compensated HBAR is particularly suited for a voltage controlled oscillator for a local oscillator of a chip-scale atomic clock.

\section{ACKNOWLEDGEMENT}

This material is based on work supported by Defense Advanced Research Projects Agency (DARPA) under contract \# N66001-02-1-8918.

\section{REFERENCES}

[1] T. W. Grudkowski, J. F. Black, T. M. Reeder, D. E. Cullen, and R. A. Wagner, "Fundamental-mode VHF/UHF minature acoustic resonators and filters on silicon," Appl. Phys. Lett., vol. 37, pp. 993-995, 1980.

[2] K.M. Lakin and J.S. Wang, "Acoustic Wave bulk composite resonators," Appl. Phys. Lett., vol. 38, pp. 125-127, 1981.

[3] K. Nakamura, H. Sasaki, and H. Shimizu, " $\mathrm{ZnO} / \mathrm{SiO} 2$ diaphragm composite resonator on a silicon wafer," Electron. Lett., vol. 17, pp. 507-509, 1981.

[4] J.T. Haynes, M. S. Buchalter, R. A. Moore, H. L. Salvo, S. G. Shepherd, B. R. McAvoy, " Stable Microwave Source Using High Overtone Bulk Resonators," Microwave Symposium Digest, MTTS International Volume 85, Issue 1, June 1985, pp. 243 - 246

[5] H. Yu,W. Pang, H. Zhang, and E. S. Kim, "Film bulk acoustic resonator at $4.4 \mathrm{GHz}$ with ultra low temperature coefficient of resonant frequency," IEEE International Micro Electro Mechanical Systems Conference, Miami, Florida, January 30 - February 3, 2005, pp. 28-31.

[6] S. P. Caldwell, M. M. Driscoll, S. D. Stansberry, D. S. Bailey and H. L. Salvo "High-overtone, bulk acoustic resonator frequency stability improvements" Frequency Control Symposium, 1993. 47th., Proceedings of the 1993 IEEE International 2-4 June 1993 pp. $744-748$

[7] S.L. Pinkett, W.D. Hunt, B.P. Barber, and P.L. Gammel, "Determination of $\mathrm{ZnO}$ temperature coefficients using thin film bulk acoustic wave resonators," IEEE Trans. Ultra. Ferro. and Freq., vol. 49, no. 11, pp. 1491-1496, 2004.

[8] Y. Yoshino, M. Takeuchi, K. Inoue, T. Makino, S. Arai and T. Hata, "Control of temperature coefficient of frequency in zinc oxide thin film bulk acoustic wave resonators at various frequency ranges." Vacuum (2002), 66(3-4), pp. 467-472

[9] R. Ruby and P. Merchant, "Micromachined Thin Film Bulk Acoustic Resonators," IEEE International Frequency Control Symposium, 1994, pp. 135-139 